Research article

Open Access

\title{
Immunohistochemical expression of insulin-like growth factor binding protein-3 in invasive breast cancers and ductal carcinoma in situ: implications for clinicopathology and patient outcome
}

\author{
Sarah B Vestey ${ }^{1}$, Claire M Perks ${ }^{1}$, Chandan Sen ${ }^{2}$, Caroline J Calder ${ }^{2}$, Jeff MP Holly ${ }^{1}$ and \\ Zoe E Winters ${ }^{1}$
}

\author{
1 University of Bristol, Department of Clinical Sciences at South Bristol - Surgery, Bristol Royal Infirmary, Bristol, UK \\ 2Department of Histopathology, United Bristol Healthcare NHS Trust, Bristol Royal Infirmary, Bristol, UK \\ Corresponding author: Zoe E Winters, zoe.winters@bristol.ac.uk \\ Received: 17 May 2004 Revisions requested: 22 Jun 2004 Revisions received: 8 Oct 2004 Accepted: 14 Oct 2004 Published: 23 Nov 2004 \\ Breast Cancer Res 2005, 7:R119-R129 (DOI 10.1186/bcr963) \\ (C) 2004 Vestey et al.; licensee BioMed Central Ltd. \\ This is an Open Access article distributed under the terms of the Creative Commons Attribution License (http://creativecommons.org/licenses/by/ \\ 2.0), which permits unrestricted use, distribution, and reproduction in any medium, provided the original work is properly cited.
}

\begin{abstract}
Introduction Insulin-like growth factor binding protein-3 (IGFBP-3) differentially modulates breast epithelial cell growth through insulin-like growth factor (IGF)-dependent and IGFindependent pathways and is a direct (IGF-independent) growth inhibitor as well as a mitogen that potentiates EGF (epidermal growth factor) and interacts with HER-2. Previously, high IGFBP-3 levels in breast cancers have been determined by enzyme-linked immunosorbent assay and immunoradiometric assay methods. In vitro, IGFBP-3's mechanisms of action may involve cell membrane binding and nuclear translocation. To evaluate tumour-specific IGFBP-3 expression and its subcellular localisation, this study examined immunohistochemical IGFBP-3 expression in a series of invasive ductal breast cancers (IDCs) with synchronous ductal carcinomas in situ (DCIS) in relation to clinicopathological variables and patient outcome.
\end{abstract}

Methods Immunohistochemical expression of IGFBP-3 was evaluated with the sheep polyclonal antiserum (developed in house) with staining performed as described previously.

Results IGFBP-3 was evaluable in 101 patients with a variable pattern of cytoplasmic expression (positivity of $1+/ 2+$ score) in $85 \%$ of invasive and $90 \%$ of DCIS components. Strong (2+) IGFBP-3 expression was evident in 32 IDCs and 40 cases of
DCIS. A minority of invasive tumours (15\%) and DCIS (10\%) lacked IGFBP-3 expression. Nuclear IGFBP-3 expression was not detectable in either invasive cancers or DCIS, with a consistent similarity in IGFBP-3 immunoreactivity in IDCs and DCIS. Positive IGFBP-3 expression showed a possible trend in association with increased proliferation $(P=0.096)$, oestrogen receptor $(\mathrm{ER})$ negativity $(P=0.06)$ and HER-2 overexpression $(P=0.065)$ in invasive tumours and a strong association with ER negativity $(P=0.037)$ in DCIS. Although IGFBP-3 expression was not an independent prognosticator, IGFBP-3positive breast cancers may have shorter disease-free and overall survivals, although these did not reach statistical significance.

Conclusions Increased breast epithelial IGFBP-3 expression is a feature of tumorigenesis with cytoplasmic immunoreactivity in the absence of significant nuclear localisation in IDCs and DCIS. There are trends between high levels of IGFBP-3 and poor prognostic features, suggesting that IGFBP-3 is a potential mitogen. IGFBP-3 is not an independent prognosticator for overall survival or disease-free survival, to reflect its dual effects on breast cancer growth regulated by complex pathways in vivo that may relate to its interactions with other growth factors.

Keywords: clinicopathology, ductal carcinoma in situ, IGFBP-3, immunohistochemistry, prognosis

\section{Introduction}

Insulin-like growth factors (IGF-I and IGF-II) regulate the cellular growth of normal and malignant breast epithelial cells with a role in malignant transformation [1-3]. IGFs are potent mitogens and are synergistic with oestrogen and epidermal growth factor (EGF) to stimulate cellular

$\mathrm{cc}=$ Spearman correlation coefficient; DCIS = ductal carcinoma in situ; DFS = disease-free survival; ER = oestrogen receptor; GPG = good prognostic group; HPF = high-power field; IDC = invasive ductal cancer; IGF = insulin-like growth factor; IGFBP-3 = insulin-like growth factor binding protein-3; IHC = immunohistochemistry; MAPK = mitogen-activated protein kinase; MPG = moderate prognostic group; NPI = Nottingham Prognostic Index; OS = overall survival; PPG = poor prognostic group; TBS = Tris-buffered saline; VNPC = Van Nuys Pathologic Classification. 
proliferation[4]. The IGFs are modulated by a family of six high-affinity IGF binding proteins, of which IGFBP-3 predominates in serum and is upregulated in breast cancer cell lines, including breast epithelium $[1,5,6]$. Both IGFs (IGF-I and (GF-II) have a preferential stromal expression and together with epithelial IGFBP-3 have a significant paracrine influence on breast epithelial growth [1,7]. IGFBPs have multiple and complex functions that can be either IGF dependent or IGF independent. With respect to IGFdependent function, IGFBP-3 preferentially binds IGFs to either inhibit or activate IGF mitogenic effects in vitro, through blocking the IGF-receptor interaction, in contrast to a prolongation of IGFs' half-life and their protection from degradation [1-3]. IGFBP-3 is pro-apoptotic in an IGFdependent manner, as well as an IGF-independent manner, and enhances the p53 DNA damage response in vitro $[8,9]$. The particular significance of IGFBP-3 in regulating epithelial cell growth has been highlighted because the actions of many growth inhibitors, apoptotic agents and anti-cancer treatments (transforming growth factor- $\beta$, retinoids, p53 and anti-oestrogens) are, at least in part, mediated by their ability to stimulate local IGFBP-3 production [1-3].

Through complex and as yet poorly understood mechanisms, IGFBP-3 is a direct (IGF-independent) growth inhibitor as well as a mitogen on breast epithelial cells $[10,11]$. Further, IGFBP-3 inhibits oestradiol-stimulated cell proliferation in breast cancer cell lines, with the potential to accentuate ceramide and paclitaxel-induced apoptosis directly [12-14]. By contrast, accumulating evidence in vitro suggests the potential mitogenicity of IGFBP-3 through its interactions with EGF receptor (EGFR) and Ras-p44/42 mitogen-activated protein kinase (MAPK) signalling in breast epithelial cells [15-18]. Postulated mechanisms for IGFBP-3's direct intrinsic actions on cell growth and apoptosis have not as yet characterised a definitive cell membrane receptor or the necessity for IGFBP-3 cell surface interaction or nuclear translocation[19]. Intracellular trafficking of IGFBP-3 with nuclear localisation in T47D breast cancer cells is explicable through a carboxy-terminal nuclear localisation signal and importin- $\beta$-mediated nuclear transport $[15,20,21]$. At present, the functional implications of nuclear IGFBP-3 are unknown[22].

Complex IGFBP-3 modulation of breast cancer growth has prompted several studies to examine levels of IGFBP-3 in breast cancer tissues in relation to clinicopathological characteristics and patient outcome [23-26]. Circulating IGFBP-3 may avert breast cancer development, with the clinical paradox that increasing IGFBP-3 levels in breast tumours may indicate adverse prognostic cancers $[2,23-$ 26 . This reflects the complexity of IGFBP-3 effects on cell proliferation and its potential role as a mitogen as well as a growth inhibitor. Poor prognostic tumours with increasing
IGFBP-3 expression may relate to recent evidence in vitro in which the pro-apoptotic action of IGFBP-3 is reversed by the extracellular matrix protein fibronectin[27,28]. In keeping with these findings, high levels of fibronectin expression are associated with poor prognostic breast cancers $[6,29]$. IGFBP-3 interacts with integrin-receptor signalling with modulation by fibronectin to increase cell attachment and possible resistance to apoptosis[27].

The aim of this first immunohistochemical study was to evaluate breast epithelial IGFBP-3 expression in relation to clinicopathological parameters and prognosis in breast cancer. IGFBPs are upregulated in malignant breast epithelial cells with evidence in vivo that IGFBP-5 is overexpressed in the cytoplasm of breast cancers and their lymph node metastases on tissue microassay immunohistochemistry (IHC) [6]. Accumulating evidence in vitro supports the dual effects of IGFBP-3 on the cellular growth of breast epithelial cells to emphasise the importance of selectively analysing breast epithelial IGFBP-3 expression in comparison with the stroma. By contrast, previous studies have collectively assessed breast epithelial and stromal IGFBP-3 levels by using immunoassay and immunoblot or ligand blot methods [23-26]. Moreover, both the histological location of IGFBP-3 and variations in its immunoreactivity have been compared in this series of invasive ductal breast cancers with concomitant evaluation of IGFBP-3 expression in synchronous ductal carcinoma in situ (DCIS) within the same tumour specimens. Increasing IGFBP-3 levels in breast tumours may indicate adverse prognostic cancers, with contradictory implications on patient outcomes $[24,25]$ to reflect the complexity of IGFBP-3 effects on cell proliferation $[27,28,30]$. We have shown a varying pattern of epithelial IGFBP-3 cytoplasmic expression ( $1+/ 2+$ score) in $85 \%$ of invasive ductal cancers (IDCs) and $90 \%$ of DCIS components, without detectable nuclear immunoreactivity. Increasing levels of IGFBP-3 expression showed a trend with increased proliferation, oestrogen receptor (ER) negativity and HER-2 overexpression to suggest its association with poor prognostic tumours.

\section{Methods \\ Patients}

The study included 103 patients aged from 26 to 88 years (median 59 years) with IDC of the breast, in association with concomitant DCIS diagnosed between 1996 and 2000 at the Bristol Royal Infirmary, Bristol, UK (Table 1). Patient numbers in clinicopathological subgroups reflect those in whom IGFBP-3 was evaluable. Regional Ethics Committee approval was granted before the start of the study. Axillary lymphadenopathy was evaluable in 88 patients; $37(42 \%)$ were lymph-node-negative and 51 $(58 \%)$ were lymph-node-positive (N1, mobile ipsilateral, or N2, fixed ipsilateral) patients. No axillary surgery was undertaken in the remaining 13 patients because of age-related 


\section{Table 1}

\begin{tabular}{|c|c|c|c|c|c|}
\hline \multirow[t]{2}{*}{ Characteristic } & \multicolumn{3}{|c|}{ IGFBP-3 score } & \multirow[t]{2}{*}{$P$} & \multirow[t]{2}{*}{ No. of patients } \\
\hline & Negative & Weak $(1+)$ & Strong (2+) & & \\
\hline Invasive tumours & 15 & 54 & 32 & & $101^{*}$ \\
\hline \multicolumn{6}{|l|}{ Age (years) } \\
\hline$\leq 50$ & 1 & 13 & 13 & 0.04 & 27 \\
\hline$>50$ & 14 & 41 & 19 & & 74 \\
\hline \multicolumn{6}{|l|}{ Lymph node status } \\
\hline Negative & 7 & 17 & 13 & 0.216 & 37 \\
\hline Positive & 4 & 31 & 16 & & 51 \\
\hline Not assessed & & & & & 13 \\
\hline \multicolumn{6}{|l|}{ IDC grade } \\
\hline 1 & 2 & 9 & 5 & 0.836 & 16 \\
\hline$\|$ & 9 & 24 & 17 & & 50 \\
\hline III & 4 & 21 & 10 & & 35 \\
\hline \multicolumn{6}{|l|}{ IDC size } \\
\hline$\leq 2 \mathrm{~cm}$ & 9 & 26 & 17 & 0.720 & 52 \\
\hline$>2 \mathrm{~cm}$ & 6 & 27 & 14 & & 47 \\
\hline Multifocal & & & & & 2 \\
\hline \multicolumn{6}{|l|}{ LV invasion } \\
\hline Absent & 9 & 27 & 12 & 0.411 & 48 \\
\hline Present & 6 & 26 & 18 & & 50 \\
\hline Not assessed & & & & & 3 \\
\hline \multicolumn{6}{|l|}{ NPI } \\
\hline GPG $(<3.4)$ & 6 & 17 & 11 & 0.662 & 34 \\
\hline MPG (3.4-5.4) & 4 & 19 & 13 & & 36 \\
\hline PPG $(>5.4)$ & 1 & 11 & 4 & & 16 \\
\hline Not calculable & & & & & 15 \\
\hline \multicolumn{6}{|l|}{ ER (quick-score) } \\
\hline Positive (4-8) & 12 & 28 & 21 & 0.06 & 61 \\
\hline Negative $(0-3)$ & 2 & 24 & 9 & & 35 \\
\hline Not assessed & & & & & 7 \\
\hline \multicolumn{6}{|l|}{ HER-2 IHC } \\
\hline Negative $(0 / 1+)$ & 14 & 48 & 23 & 0.065 & 85 \\
\hline Positive $(2+/ 3+)$ & 1 & 6 & 9 & & 16 \\
\hline \multicolumn{6}{|l|}{ Ki67 IHC } \\
\hline Low proliferation $<10 \%$ & 10 & 26 & 13 & 0.249 & 49 \\
\hline High proliferation $\geq 10 \%$ & 5 & 28 & 19 & & 52 \\
\hline DCIS & & & & & $102^{*}$ \\
\hline
\end{tabular}


Table 1 (Continued)

\begin{tabular}{|c|c|c|c|c|c|}
\hline Grade I & 1 & 14 & 8 & 0.586 & 23 \\
\hline Grade II & 5 & 17 & 14 & & 36 \\
\hline Grade III & 2 & 21 & 15 & & 38 \\
\hline Not assessed & & & & & 5 \\
\hline \multicolumn{6}{|l|}{ ER (quick-score) } \\
\hline Positive (4-8) & 11 & 26 & 19 & 0.037 & 56 \\
\hline Negative (0-3) & 1 & 23 & 9 & & 33 \\
\hline Not assessed & & & & & 13 \\
\hline \multicolumn{6}{|l|}{ HER-2 IHC } \\
\hline Negative $(0 / 1+)$ & 7 & 41 & 28 & 0.876 & 76 \\
\hline Positive $(2+/ 3+)$ & 2 & 9 & 8 & & 19 \\
\hline Not assessed & & & & & 7 \\
\hline \multicolumn{6}{|l|}{ Ki67 IHC } \\
\hline Low proliferation $<10 \%$ & 6 & 30 & 24 & 0.972 & 60 \\
\hline High proliferation $\geq 10 \%$ & 4 & 22 & 16 & & 42 \\
\hline
\end{tabular}

DCIS, ductal carcinoma in situ; ER, oestrogen receptor; GPG, good prognostic group; IHC, immunohistochemistry; MPG, moderate prognostic group; NPI, Nottingham Prognostic Index; PPG, poor prognostic group; VNPC, Van Nuys Pathologic classification. Significant $P$ values $(P<0.05)$ are indicated in bold.

*Patient numbers reflect those in whom IGFBP-3 was evaluable.

co-morbidity. Clinicopathological subgroups were analysed in accordance with the Nottingham Prognostic Index (NPI) and divided into good (GPG), moderate (MPG) and poor (PPG) prognostic groups as described, with a modification that included no assessment of the internal mammary lymph nodes[31]. Evaluation of the NPI was precluded in 15 patients because of non-evaluable regional lymphadenopathy and tumour size. Similarly, subgroups of DCIS were analysed in accordance with the Van Nuys Pathologic Classification (VNPC) (Table 1), which was not assessable in five patients [32]. The design of the study to include tumour representative samples of synchronous IDC and DCIS precluded the analysis of the Van Nuys Prognostic Index[32]. Adjuvant treatment groups comprised the following: tamoxifen in 60 patients (27 GPG, 16 MPG, 4 PPG and 13 no NPI), and CMF-containing and anthracyclinecontaining regimes in 17 and 21 patients, respectively (4 GPG, 19 MPG, 13 PPG and 2 no NPI). Five patients received no adjuvant treatment. The median follow-up duration was 51 months (range 4-120 months). All were primary tumours with the exception of six local tumour recurrences, which were excluded from the analysis of patient outcome (see Table 3 and Fig. 2).

Tumour samples were collected and freshly fixed in buffered formalin in accordance with a standardised protocol at a single institution. Tumours were classified in accordance with NHSBSP guidelines [33]. Invasive ductal carcinomas were graded by the modified Bloom's grading system described by Elston and Ellis[34]. ER immunostaining was performed with a standard three-layered streptavidin-avidin-biotin horseradish peroxidase method with a mouse anti-human ER primary antibody (M0747, 1:100 dilution; DAKO, Ely, Cambridgeshire, UK) and a biotinylated rabbit anti-mouse secondary antibody (E354, 1:350 dilution; DAKO). Expression of ER was assessed with the quickscore $(0-8)$ and classified as positive $(4-8 ;>3)$ or negative $(0-3 ; \leq 3)$ in five high-power fields (HPFs) [35]. Tumour proliferation was assessed with nuclear Ki67 immunostaining (polyclonal rabbit anti-human Ki67 antigen; A0047, 1:100 dilution; DAKO). A goat anti-rabbit biotin-labelled polypeptide (E432, 1:400 dilution; DAKO, Glostrup, Denmark) was used as a secondary antibody.

Tonsillar tissue was used as a positive control and primary antibody was replaced with Tris-buffered saline (TBS) as a negative control. Ki67 staining was evaluated as percentage of positive tumour cells, with low proliferation indicative of $<10 \%$ of positive-staining cells, compared with high proliferation with $\geq 10 \%$ positivity [36]. HER-2 immunostaining was performed with the mouse monoclonal anti-HER-2 antibody (RTU-CB11; Novocastra/Vector, Newcastle upon Tyne, UK), and the Envision Plus HRP system (K4006; DAKO). HER-2 expression was scored according to the degree and proportion of membrane staining, with a score of 0 or $1+$ defined as negative, and $2+$ or $3+$ as HER-2 positive[37]. Lymphovascular invasion was assessed as present or not, and together with ER, HER-2 
and Ki67 was analysed in the Department of Pathology (by CS and CC).

\section{Immunohistochemistry}

IGFBP-3 immunoreactivity was evaluated with the in-house sheep polyclonal antiserum (Professor JMP Holly, IGF Research Group, University of Bristol, Bristol, UK) at 1:800 dilution[9]. IGFBP-3 immunostaining of IDC and DCIS was compared with formalin-fixed normal liver tissue as a positive control for IGFBP-3, and a replacement of the primary antibody with TBS as a negative control. Validation and specificity of the sheep polyclonal in-house antiserum has previously been demonstrated with an IGFBP-3 peptide on immunocytochemistry of Hs578T breast cancer cells[38].

Formalin-fixed paraffin sections of breast cancer tissue and normal liver tissue were mounted on glass slides coated with 3-aminopropyl-triethoxysilane (APES; Sigma, Poole, Dorset, UK) and were baked for $30 \mathrm{~min}$ at $56-60^{\circ} \mathrm{C}$, before being dewaxed in Clearene (Surgipath Europe, Peterborough, UK). The tissue was rehydrated by sequential immersion in 100\% and 50\% ethanol to distilled water. Tissue sections were subjected to heat antigen retrieval for $3 \mathrm{~min}$ in citrate buffer ( $\mathrm{pH} \mathrm{6)}$ in a pressure cooker, and after cooling were incubated for $5 \mathrm{~min}$ in $0.3 \%(\mathrm{v} / \mathrm{v})$ hydrogen peroxide. Subsequently, sections were washed in tap water and TBS ( $\mathrm{pH}$ 7.45). Before incubation with IGFBP-3 primary antibody, sections were exposed to avidin and biotin blocking solutions (Vector Laboratories, Burlingame, CA, USA) for $15 \mathrm{~min}$, respectively. Further blocking was achieved through exposure to normal rabbit serum (diluted with TBS) for $30 \mathrm{~min}$ at room temperature $\left(20-22^{\circ} \mathrm{C}\right)$. Primary antibody was applied and incubated overnight at $4^{\circ} \mathrm{C}(18$ hours). After washing with TBS, biotinylated rabbit antigoat secondary antibody, together with the Strept-AB Complex/HRP (0377, DAKO, Glostrup, Denmark) was applied for $30 \mathrm{~min}$ at room temperature. Staining was revealed by development in the chromogen 3,3-diaminobenzidine tetrahydrochloride (DAB) for 5-10 min before counterstaining with haematoxylin in preparation for mounting.

Immunostaining was assessed with a Zeiss Axioskop microscope with a $40 \times$ Achrostigmat lens ( $\times 400$ overall magnification) and a field diameter of $0.46 \mathrm{~mm}$. In the neoplastic cell population for IDC and DCIS, the degree of staining intensity and the proportion of cells with IGFBP-3 immunoreactivity in the nucleus and cytoplasm were graded semi-quantitatively to produce an intensity distribution score for each localisation, with invasive and pre-invasive components given separate scores. Initial scoring was of 10 HPFs; however, in view of the homogeneous staining, this was reduced to 5 HPFs. Sections were scored independently by two observers and were scored as follows: negative $(0)$, weak/moderately positive $(1+)$ or strongly positive $(2+)$, with DCIS and invasive components scored independently. Scores were assessed as a continuum for the purposes of statistical correlation, unless otherwise stated.

\section{Statistical analysis}

Data were analysed with the SPSS 10.0 for Windows statistics software and summarised with descriptive statistics. The associations between IGFBP-3 and patient characteristics were assessed with the Spearman non-parametric test for continuous variables and the $\chi^{2}$ test for categorical factors. Analyses of survival data were performed with the log-rank test and the Cox regression model, and survival curves were computed with the Kaplan-Meier method. For IGFBP-3, univariate and multivariate analyses were performed, the latter adjusting for NPI score and treatment received (tamoxifen/chemotherapy/none). Because the $\mathrm{NPI}$ is based on nodal involvement, on tumour size and on grade, patients $(n=11)$ with non-evaluable lymphadenopathy and tumour size were excluded from the multivariate regression analyses (see Table 3 ).

\section{Results IGFBP-3 expression in IDCs and DCIS and their relationships to clinicopathological factors}

IGFBP-3 immunoreactivity was evaluable in 101 (98\%) cases of IDCs and in 102 cases of DCIS, and scored positively $(1+/ 2+)$ as a homogeneous cytoplasmic expression in $86(85 \%)$ of invasive and 92 (90\%) of DCIS components (Fig. 1; Tables 1 and 2). Strong (2+) IGFBP-3 expression was seen in 32 invasive breast cancers and 40 cases of DCIS. A weak/moderate $(1+)$ expression of IGFBP-3 was evident in the majority of invasive $(n=54)$ and DCIS $(n=$ 52) components. There was no clear evidence of nuclear IGFBP-3 expression on IHC in IDC or DCIS. Consistently low levels of IGFBP-3 were evident throughout the stroma, without strong expression except in vascular endothelial cells. A comparison showed that the levels of IGFBP-3 expression in DCIS were similar to those in invasive disease (Table 2).

We investigated the relationships between the levels of IGFBP-3 expression and clinicopathological parameters in IDCs and DCIS. IGFBP-3 scores were analysed as a continuum for the purposes of statistical analysis. There were no significant associations (where data was assessed as a continuum) between IGFBP-3 and established prognostic indicators in invasive disease (lymph node involvement, increasing tumour size, increasing tumour histological grade, ER negativity [quick-score 0-8], lymphovascular invasion and NPI). There was a possible trend between increasing IGFBP-3 levels and increasing cellular proliferation (Ki67) in invasive disease (Spearman correlation coefficient [cc] 0.166, $P=0.096$ ) (where assessed as a continuum) that was not observed in DCIS $(P=0.8)$ (data 
Figure 1
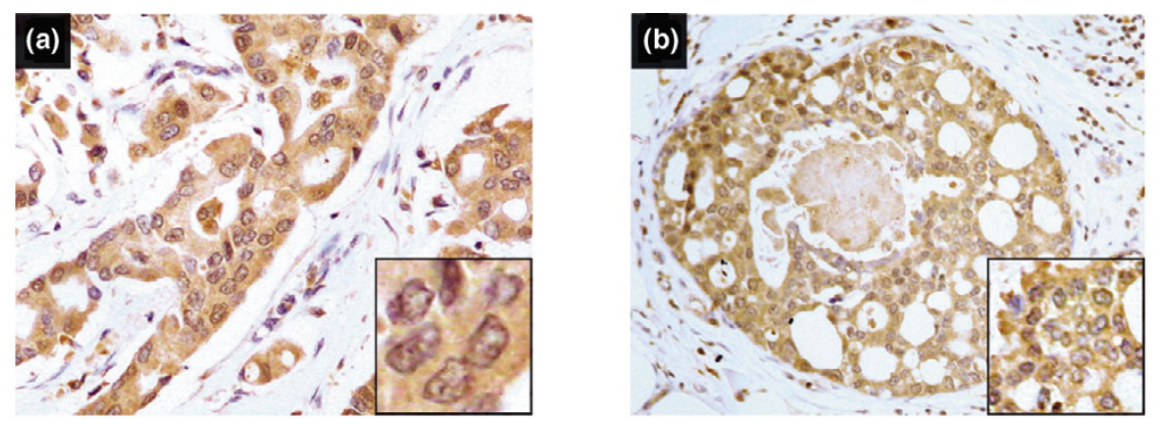

Examples of IGFBP-3 immunoreactivity in infiltrating ductal carcinoma of the breast with concomitant DCIS. Immunostaining was performed as described in the Methods section, and nuclei were counterstained with haematoxylin. (a) A tumour showing cytoplasmic IGFBP-3 expression in invasive ductal cancer. (b) A similar cytoplasmic IGFBP-3 positivity in concomitant DCIS. High-power magnification (original magnification $\times 400$ ).

Table 2

Immunohistochemical (IHC) scores (0-2) for IGFBP-3 expression in the cytoplasm of invasive ductal cancers and ductal carcinoma in situ

\begin{tabular}{lcccc}
\hline Cancer type & Total no. of tumours & \multicolumn{3}{c}{ IGFBP-3 IHC score } \\
\cline { 3 - 5 } & & Negative (0) & Weak/moderate (1+) & Strong (2+) \\
\hline Invasive & 101 & 15 & 54 & 32 \\
DCIS & 102 & 10 & 52 & 40 \\
\hline
\end{tabular}

Tumour numbers scored (0-2) on immunohistochemistry (IHC) for IGFBP-3 expression in the cytoplasm of invasive cancers and ductal carcinoma in situ (DCIS). IHC expression was individually assessed in the nucleus and cytoplasm, and defined as negative (0), weak/moderate (1+) or strong (2+). Positivity for IGFBP-3 expression was defined as an IHC score of $(1+/ 2+)$.

not shown), or where Ki67 was categorised as $<10 \%$ versus $\geq 10 \%$ (Table 1). A comparison of categorical IGFBP3 expression with ER-positive (quick-score 4-8) and ERnegative (quick-score $0-3$ ) IDCs showed a trend $(P=$ $0.06)$ with ER-negative tumours and HER-2-positive invasive tumours $(P=0.065$ ) (Table 1). In Table 1, 94\% (33 of 35) of ER-negative cancers expressed either $1+$ or $2+$ IGFBP-3 versus $80 \%$ of ER-positive tumours ( $\chi^{2}$ test, $P=$ 0.06). Similarly, $94 \%$ (15 of 16 ) of HER-2-positive tumours expressed IGFBP-3 $(1+/ 2+)$ versus $84 \%$ of HER-2-negative cancers $(P=0.065)$.

There were no associations between IGFBP-3 expression and pathological variables on logistic regression in DCIS (VNPC, HER-2 expression and increased proliferation/ Ki67). A categorical analysis of individual IGFBP-3 scores (negative versus $1+$ versus $2+$ ) in DCIS showed that $97 \%$ (32 of 33) of IGFBP-3-positive DCIS were ER-negative versus $80 \%$ of ER-positive DCIS $(P=0.037)$ (Table 1$)$. We demonstrated an inverse correlation between local IGFBP3 expression and patient age, in which IGFBP-3 immunoreactivity analysed on a continuum decreased with age (cc $0.214, P=0.03$ ) (data not shown); Table 1 shows a significant association with age $(P=0.04)$ when IGFBP-3 and age are analysed categorically in the invasive components, with a possible trend in DCIS (cc $-0.174, P=0.08$ ) (data not shown).

\section{Relationships of clinicopathological factors to prognosis} and the predictive potential of IGFBP-3 expression

Overall survival (OS) and disease-free survival (DFS) were determined in 87 and 95 patients, respectively, with a median follow-up of 51 months (range 4-120 months). Disease relapses (local or distant recurrences) occurred in 30 women; of these, deaths were confirmed in 23 patients, with 8 suspected deaths in the absence of a recorded mortality date. Locoregional recurrence occurred at a median duration of 28.5 months (range 3-156 months) from diagnosis. Breast cancer-related mortality occurred at a median of 26 months (range 8-98 months) from presentation. The mean durations of OS and DFS were 93 months and 87 months, respectively. Four-year DFS and OS were $70 \%$ and $77 \%$, respectively. The relationship of established clinicopathological features with OS and DFS were analysed with Cox's regression analysis (Table 3). Generally poor prognostic factors such as large tumour size, high tumour grade, lymphovascular invasion, lymph node metastases, ER negativity, HER-2 overexpression and NPI were significantly associated with decreased OS and DFS. High tumour proliferation (Ki67 on $\mathrm{IHC}$ ), although associated 
Figure 2
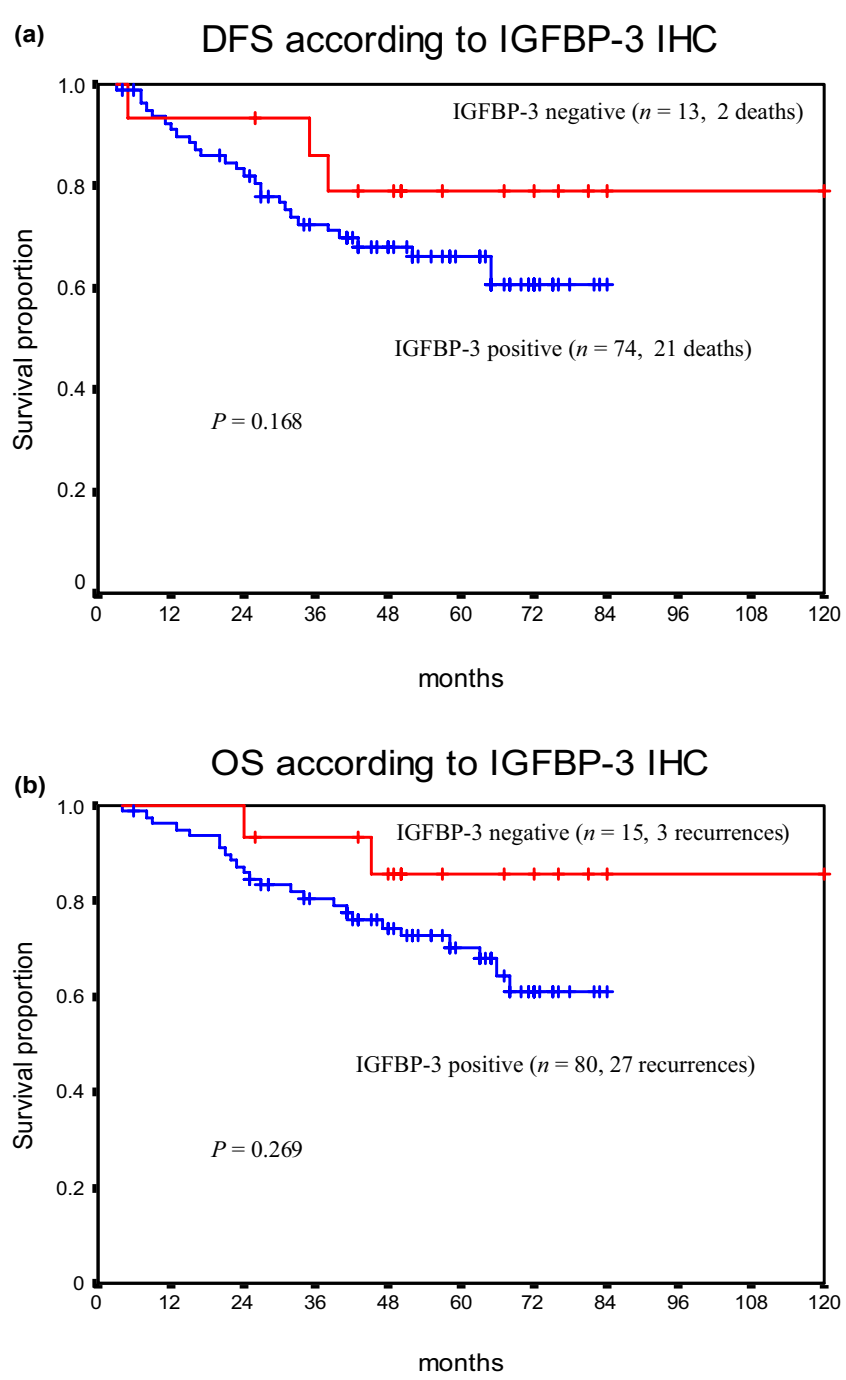

The relationship of IGFBP-3 to disease-free survival (DFS) and overall survival (OS). DFS (a) and OS (b) curves according to IGFBP-3-positive $(1+/ 2+)$ and IGFBP-3-negative (0) breast cancers. The patient numbers reflect the exclusion of six local tumour recurrences as described in the Methods section, and include only recorded deaths in 23 patients. The $P$ values are given for the log ranks.

with a lower percentage of patients remaining disease-free (DFS) and alive (OS) at 4 years, did not reach statistical significance.

Univariate and multivariate analysis with the continuous score variables were used to investigate possible relationships between patient outcome data and levels of expression for IGFBP-3. IGFBP-3 scores (assessed as a continuum) were not predictive for OS or DFS after univariate or multivariate analysis (Table 3), adjusted for NPI and adjuvant treatment (tamoxifen/chemotherapy/none) with respect to the multivariate analysis. Where IGFBP-3 was categorised as positive $(1+/ 2+)$ or negative $(0)$, the Kap-
lan-Meier survival curves (Fig. 2) demonstrate a possible trend towards a more favourable outcome for IGFBP-3negative tumours, although this failed to reach statistical significance for OS $(P=0.168)$ or DFS $(P=0.269)$, perhaps related in part to the small numbers of IGFBP-3negative tumours observed in this study.

\section{Discussion}

IGFBP-3 has direct intrinsic actions, as well as regulating IGFs to influence cellular growth, survival and apoptosis of breast epithelial cells. Breast cancer cells typically express several IGFBPs, with IGFBP-2, IGFBP-3, IGFBP-4 and IGFBP-5 being observed most often $[5,6,22]$. Although previous studies in vivo have suggested a tumour-related upregulation of IGFBP-3 levels, clinical studies have yet to determine IGFBP-3 epithelial protein expression in breast cancers; this is the first IHC study. IHC of tissue microassays confirms a tumour-specific upregulation of IGFBP5 and IGFBP-2 in primary breast cancers and their lymph node metastases [6]. The significance of these findings in the context of a decreased mRNA expression for IGFBP-5 and IGFBP-2, respectively, highlights the value and clinical contribution of an immunohistochemical evaluation[6]. Furthermore, a tumour-specific pathway is implicated, with negligible levels of IGFBP-5 and IGFBP-2 in normal breast epithelial cells $[6,39,40]$. Increasing levels of IGFBP-3 in breast cancer tissues correlate with poor prognostic features, as demonstrated in four studies in vivo through enzyme-linked immunosorbent assay and immunoradiometric assay [23-26]. The admixture of tumour with normal and stromal breast tissue is a feature of both quantitative methods with possible limitations regarding the evaluation of a predominant tumour-specific epithelial protein.

No studies have yet clarified IGFBP-3 expression on IHC in invasive breast cancers in comparison with DCIS, although there has been a limited review of colorectal carcinomas and normal colonic mucosa[9]. This study suggests that most breast cancers express epithelial IGFBP-3 $(1+/ 2+)$, mostly with a weak/moderate immunoreactivity (1+). Fewer tumours expressed IGFBP-3 strongly $(2+)$ and it was evident more frequently in DCIS. Similar genomic aberrations may occur in DCIS and IDC to highlight possible similarities in protein expression $[41,42]$. This study, in large part, shows a consistent similarity in the levels of IGFBP-3 expression in DCIS and IDC (cc 0.789; $P<0.001$ ) (Table 2).

Nuclear localisation of IGFBP-3 has been described in several cell lines in vitro, including breast cancer cells $[20,21]$. This observation is supported by the direct interaction of IGFBP-3 with the nuclear receptor retinoid $X$ receptor and the ability of IGFBP-3 to act as a nuclear-import carrier for IGF-I[20,22,43]. This has raised considerable interest in the potential nuclear actions of IGFBP-3 and its functional 
Table 3

Relationships between clinicopathological criteria, cytoplasmic IGFBP-3 and patient outcome

\begin{tabular}{|c|c|c|c|c|}
\hline \multirow[t]{2}{*}{ Variable } & \multicolumn{2}{|c|}{ Univariate analysis } & \multicolumn{2}{|c|}{ Multivariate analysis } \\
\hline & $95 \% \mathrm{Cl}$ & $P$ & $95 \% \mathrm{Cl}$ & $P$ \\
\hline \multicolumn{5}{|l|}{ Overall survival } \\
\hline Age & $0.99-1.04$ & 0.4 & $0.98-2.90$ & 0.009 \\
\hline Lymph node status (+/-) & $2.79-153.9$ & 0.004 & $2.65-161$ & 0.003 \\
\hline Invasive tumour grade (I, II, III) & $1.27-4.93$ & 0.002 & $1.14-4.62$ & 0.002 \\
\hline Tumour size & $1.02-1.05$ & $<0.001$ & $1.02-1.05$ & $<0.001$ \\
\hline NPI & $1.48-3.36$ & $<0.001$ & $1.39-3.32$ & $<0.001$ \\
\hline ER (quick-score) & $0.66-0.92$ & 0.002 & $0.68-0.98$ & 0.03 \\
\hline HER-2 IHC score & $0.94-2.02$ & 0.04 & $0.76-1.95$ & 0.56 \\
\hline Ki67 proliferative index & $0.99-1.00$ & 0.4 & $0.99-1.00$ & 0.65 \\
\hline Lymphovascular invasion (+/-) & $1.46-9.38$ & 0.006 & $0.89-6.69$ & 0.08 \\
\hline IGFBP-3 IHC score & $0.62-2.01$ & 0.719 & $0.59-2.50$ & 0.592 \\
\hline \multicolumn{5}{|l|}{ Disease-free survival } \\
\hline Age & $0.97-1.02$ & 0.9 & $0.99-1.06$ & 0.06 \\
\hline Lymph node status (+/-) & $2.29-25.3$ & $<0.001$ & $2.06-25.6$ & 0.002 \\
\hline Invasive tumour grade (I, II, III) & $1.48-5.38$ & 0.005 & $1.36-5.11$ & 0.006 \\
\hline Tumour size & $1.02-1.04$ & $<0.001$ & $1.02-1.04$ & $<0.001$ \\
\hline NPI & $1.46-3.17$ & $<0.001$ & $1.38-3.15$ & $<0.001$ \\
\hline ER (quick-score) & $0.66-0.89$ & 0.001 & $0.68-0.95$ & 0.01 \\
\hline HER-2 IHC score & $1.04-1.92$ & 0.02 & $0.95-1.87$ & 0.2 \\
\hline Ki67 proliferative index & $0.99-1.00$ & 0.2 & $0.99-1.00$ & 0.3 \\
\hline Lymphovascular invasion (+/-) & $1.63-6.95$ & 0.002 & $1.09-6.65$ & 0.03 \\
\hline IGFBP-3 IHC score & $0.61-1.71$ & 0.922 & $0.57-1.90$ & 0.896 \\
\hline
\end{tabular}

Confidence intervals $(\mathrm{Cl})$ and $P$ values are given for the results of both the univariate and multivariate analyses. The multivariate analysis is adjusted for Nottingham Prognostic Index (NPI) (nodes, grade and size) and treatment (tamoxifen/chemotherapy/none). Data for univariate analysis were evaluable in 95 patients (reflecting the exclusion of six local tumour recurrences as described in the Methods section) and included a multivariate analysis on 84 cases that excluded non-evaluable NPI in 11 patients. All clinicopathological variables and cytoplasmic IGFBP-3 immunohistochemistry (IHC) scores were analysed as a continuum, with lymph node status and lymphovascular invasion assessed as present or absent. Significant $P$ values $(P<0.05)$ are indicated in bold.

ER, oestrogen receptor.

implications. There have been very few observations of nuclear localisation of IGFBPs in vivo, with cytoplasmic IGFBP-5 expression in breast tumours and, similarly, cytoplasmic IGFBP-3 in normal colonic crypts[6,9]. Moreover, there is further evidence in vitro suggesting that IGFBP-3 growth modulation might be independent of nuclear translocation[19]. In the 101 samples of IDC and DCIS analysed in the study, we observed no evidence of nuclear staining for IGFBP-3.

IGFBP-3 modulates cellular proliferation with dual actions that either enhance IGFs or inhibit their actions. By contrast, in IGF-unresponsive Hs578T breast cancer cells,
IGFBP-3 is predominantly growth-inhibitory and pro-apoptotic $[11,27]$. Similarly, there is a potential for IGFBP-3 to switch its action on cell survival in Hs578T cells through changes in the extracellular matrix, with a clear reversal of IGFBP-3 accentuation of apoptosis when cells are changed from being grown on either plastic, collagen or laminin to fibronectin[27]. This suggests that IGFBP-3 might be preferentially activating integrin receptors that bind fibronectin in a pro-survival growth stimulatory pathway $[44,45]$. Upregulation of fibronectin expression is a feature of breast cancer metastases and poor prognostic tumours, with evidence of IGFBP-3 binding to this mesenchymal extracellular matrix glycoprotein[29,46,47]. 
Tumour-related upregulation of IGFBP-3 levels in aggressive breast cancers is only partly explicable by the described findings in vitro.

Evidence is accumulating that IGFBP-3 is a potential mitogen that interacts with EGFR and HER-2 signalling pathways $[16-18,28]$. The potential to switch the IGFBP-3 action on cell growth suggests that IGFBP-3 has a role in malignant progression of breast cancer cells with insensitivity to IGFBP-3 growth inhibition through the expression of oncogenic Ras [17]. This is further supported by four clinical studies of breast tumours, including the present study demonstrating a spectrum of increased IGFBP-3 levels, with the highest expression indicative of a more malignant phenotype [23-26]. Increasing passages of T47D cells switch their response to IGFBP-3 with increasing tumorigenicity, although initially growth-inhibited by this binding protein [18]. Dual growth modulation by IGFBP-3 is demonstrated in MCF10A cells, in which IGFBP-3 changes from a growth inhibitor to a mitogen through Rasinduced malignant transformation and activation of Rasp44/42 MAPK $[16,17]$. Normal breast epithelial MCF10A cells exposed to increasing doses of IGFBP-3 show a similar biphasic response, with preliminary growth inhibition followed by IGFBP-3 mitogenicity in the context of an IGFI receptor antagonist, or a serine phosphorylation domain peptide (SPD, a non-IGF binding peptide), to verify these IGF-independent effects[11,48]. LNCaP prostate cancer cells are similarly growth-stimulated by IGFBP-3 independently of IGFs [49].

In this study we found a possible association with increased proliferation, together with other adverse prognostic features such as ER negativity and HER-2 overexpression. Elevated IGFBP-3 expression might therefore suggest an abundance of IGFs sequestered by the binding protein, with further implications of an IGF-independent mitogenic role. IGFBP-3 mitogenicity may also relate to candidate proteases, such as cathepsin $D$, prostate-specific antigen and matrix metalloproteinases, with IGFBP-3 proteolysis potentially releasing IGFs to enhance their mitogenicity. The precise mechanism for this regulation remains unknown because studies so far have shown no clear correlations between IGFBP-3 and these proteins in tissue extracts.

This study suggests an association between IGFBP-3 expression and ER negativity and confirms previous findings in vivo [24,25]. Clearly, there is a significant synergism between the ER and the IGFs in breast cancer cells [1-3]. Many members of the IGF system are under transcriptional control of the ER, with IGF-I similarly enhancing the transcriptional activity of ER[1,2]. Oestrogens transcriptionally downregulate IGFBPs in breast tissue and increase IGFBP-3 proteases, which may in part explain the inverse association between IGFBP-3 and ER expression [24,25], as well as perhaps reflecting the disruption of common pathways characteristic of poor prognostic tumours [2,50,51]. HER-2 overexpression predicts aggressive and poor prognostic breast tumours that are likely to be ER negative and tamoxifen resistant[52]. Recent evidence in vitro suggests a functional interaction between the IGF-I receptor and HER-2, with the potential for IGFBP-3 to modulate this response[53,54]. Our finding of an association between IGFBP-3 and HER-2 expression is preliminary and, although based on a limited number of HER-2-positive tumours, may suggest a role for HER-2 in IGFBP-3 growth modulation. In vitro, IGFBP-3 promotes EGF in HER-2overexpressing T47D and Hs578T breast cancer cells $[18,28,30]$. Ageing is associated with profound changes in the growth hormone/IGF regulatory pathways, with diminished circulating IGFBP-3, as well as decreased tissue levels previously observed in vivo and confirmed in this study $[2,25]$.

Although high levels of IGFBP-3 in breast cancers are associated with poor prognostic features of the tumour, few studies have substantiated any significant implications on patient outcome[24,25]. Tissue IGFBP-3 concentrations have been reported to predict a reduced OS, but this was not associated with breast cancer recurrence [25]. This study suggests that IGFBP-3 expression in breast cancers might be associated with a shorter OS and DFS, although few patients were negative for IGFBP-3 expression. Other studies, including the present one, show a consistent negative association between IGFBP-3 expression and favourable prognostic markers underlining the potential importance of this pathway in tumorigenesis [23-26]. IGFBP-3 regulates breast cancer epithelial growth through IGF-dependent and IGF-independent pathways that involve both growth inhibition and enhanced apoptosis with the potential to switch to growth stimulatory pathways interacting with EGFR, HER-2 and fibronectin. Defining these mechanisms merits further studies in vitro and in vivo.

\section{Conclusion}

IGFBP-3 is important in tumorigenesis because of its effects on cellular proliferation, survival and apoptosis. We have demonstrated a tumour-associated upregulation of cytoplasmic IGFBP-3 epithelial expression in invasive and non-invasive breast cancers, with similar patterns of immunoreactivity. Despite evidence in vitro and functional implications, no nuclear IGFBP-3 expression was detectable on IHC. Invasive breast cancers expressing IGFBP-3 showed an association with poor prognostic features including increased proliferation, ER negativity and HER-2 overexpression, with possible implications for patient outcome. IGFBP-3 is a growth modulator with the potential to switch 
from a growth inhibitor to a mitogen that interacts with the EGFR family.

\section{Competing interests}

The author(s) declare that they have no competing interests.

\section{Authors' contributions}

SBV carried out the immunohistochemistry for IGFBP-3 as well as the clinical and statistical analyses. CMP established conditions for testing the IGFBP-3 antibody and together with JMPH has contributed to the development of the in-house antibody. CS evaluated all scoring of IGFBP3 expression and performed all histopathology review. CJC evaluated the IGFBP-3 scoring and re-reviewed all histopathology. JMPH developed the IGFBP-3 antibody and conditions for its application, as well as conceiving the study. ZEW conceived the study, and participated in the study design, statistical analyses and wrote the manuscript. All authors read and approved the final manuscript.

\section{Acknowledgements}

We thank Rosemary Greenwood (Statistician, Department of Research and Development, United Bristol Healthcare NHS Trust) for her contribution to statistical analyses, and Mr Paul Newcomb (Department of Medicine, University of Bristol) for his technical assistance. This work was funded by the Association of International Cancer Research.

\section{References}

1. Sachdev D, Yee D: The IGF system and breast cancer. Endocr Relat Cancer 2001, 8:197-209.

2. $\mathrm{Yu} \mathrm{H}$, Rohan $\mathrm{T}$ : Role of the insulin-like growth factor family in cancer development and progression. J Natl Cancer Inst 2000, 92:1472-1489.

3. Grimberg A, Cohen P: Role of insulin-like growth factors and their binding proteins in growth control and carcinogenesis. $J$ Cell Physio/ 2000, 183:1-9.

4. Ahmad T, Farnie G, Bundred NJ, Anderson NG: The mitogenic action of insulin-like growth factor I in normal human mammary epithelial cells requires the epidermal growth factor receptor tyrosine kinase. J Biol Chem 2004, 279:1713-1719.

5. Figueroa JA, Jackson JG, McGuire WL, Krywicki RF, Yee D: Expression of insulin-like growth factor binding proteins in human breast cancer correlates with estrogen receptor status. J Cell Biochem 1993, 52:196-205.

6. Hao X, Sun B, Hu L, Lahdesmaki H, Dunmire V, Feng $Y$, Zhang $\mathrm{SW}$, Wang $\mathrm{H}$, Wu $\mathrm{C}$, Wang $\mathrm{H}$, et al:: Differential gene and protein expression in primary breast malignancies and their lymph node metastases as revealed by combined cDNA microarray and tissue microarray analysis. Cancer 2004, 100:1110-1122.

7. Yee D, Paik S, Lebovic GS, Marcus RR, Favoni RE, Cullen KJ, Lippman ME, Rosen N: Analysis of insulin-like growth factor I gene expression in malignancy: evidence for a paracrine role in human breast cancer. Mol Endocrinol 1989, 3:509-517.

8. Hollowood AD, Lai T, Perks CM, Newcomb PV, Alderson D, Holly JM: IGFBP-3 prolongs the p53 response and enhances apoptosis following UV irradiation. Int J Cancer 2000, 88:336-341.

9. Williams AC, Collard TJ, Perks CM, Newcomb P, Moorghen M, Holly JM, Paraskeva C: Increased p53-dependent apoptosis by the insulin-like growth factor binding protein IGFBP-3 in human colonic adenoma-derived cells. Cancer Research 2000, 60:22-27.

10. Oh Y: IGF-independent regulation of breast cancer growth by IGF binding proteins. Breast Cancer Res Treat 1998, 47:283-293.
11. McCaig C, Fowler CA, Laurence NJ, Lai T, Savage PB, Holly JM, Perks CM: Differential interactions between IGFBP-3 and transforming growth factor-beta (TGF-beta) in normal vs cancerous breast epithelial cells. Br J Cancer 2002, 86:1963-1969.

12. Huynh $\mathrm{H}$, Yang $\mathrm{X}$, Pollak M: Estradiol and antiestrogens regulate a growth inhibitory insulin-like growth factor binding protein 3 autocrine loop in human breast cancer cells. J Bio/ Chem 1996, 271:1016-1021.

13. Gill ZP, Perks CM, Newcomb PV, Holly JMP: Insulin-like growth factor-binding protein (IGFBP-3) predisposes breast cancer cells to programmed cell death in a non-IGF-dependent manner. J Biol Chem 1997, 272:25602-25607.

14. Fowler CA, Perks CM, Newcomb PV, Savage PB, Farndon JR, Holly JMP: Insulin-like growth factor binding protein-3 (IGFBP3) potentiates paclitaxel-induced apoptosis in human breast cancer cells. Int J Cancer 2000, 88:448-453.

15. Firth SM, Fanayan S, Benn D, Baxter RC: Development of resistance to insulin-like growth factor binding protein-3 in transfected T47D breast cancer cells. Biochem Biophys Res Commun 1998, 246:325-329.

16. Martin JL, Weenink SM, Baxter RC: Insulin-like growth factorbinding protein-3 potentiates epidermal growth factor action in MCF-10A mammary epithelial cells. Involvement of p44/42 and p38 mitogen-activated protein kinases. J Biol Chem 2003, 278:2969-2976.

17. Martin JL, Baxter RC: Oncogenic ras causes resistance to the growth inhibitor insulin-like growth factor binding protein-3 (IGFBP-3) in breast cancer cells. J Biol Chem 1999, 274:16407-16411.

18. Butt AJ, Martin JL, Dickson KA, McDougall F, Firth SM, Baxter RC: Insulin-like growth factor binding protein-3 expression is associated with growth stimulation of T47D human breast cancer cells: the role of altered epidermal growth factor signaling. J Clin Endocrinol Metab 2004, 89:1950-1956.

19. Butt AJ, Fraley KA, Firth SM, Baxter RC: IGF-binding protein-3induced growth inhibition and apoptosis do not require cell surface binding and nuclear translocation in human breast cancer cells. Endocrinology 2002, 143:2693-2699.

20. Schedlich LJ, Young TF, Firth SM, Baxter RC: Insulin-like growth factor-binding protein (IGFBP)-3 and IGFBP-5 share a common nuclear transport pathway in T47D human breast carcinoma cells. J Biol Chem 1998, 273:18347-18352.

21. Schedlich LJ, Le Page SL, Firth SM, Briggs LJ, Jans DA, Baxter RC: Nuclear import of insulin-like growth factor-binding protein- 3 and -5 is mediated by the importin beta subunit. $J$ Biol Chem 2000, 275:23462-23470.

22. Schedlich LJ, Graham LD: Role of insulin-like growth factor binding protein-3 in breast cancer cell growth. Microsc Res Tech 2002, 59:12-22.

23. Rocha RL, Hilsenbeck SG, Jackson JG, Lee AV, Figueroa JA, Yee $D$ : Correlation of insulin-like growth factor-binding protein-3 messenger RNA with protein expression in primary breast cancer tissues: detection of higher levels in tumors with poor prognostic features. J Natl Cancer Inst 1996, 88:601-606.

24. Rocha RL, Hilsenbeck SG, Jackson JG, VanDenBerg CL, Weng C, Lee AV, Yee D: Insulin-like growth factor binding protein-3 and insulin receptor substrate-1 in breast cancer: correlation with clinical parameters and disease-free survival. Clin Cancer Res 1997, 3:103-109.

25. Yu H, Levesque MA, Khosravi MJ, Papanastasiou-Diamandi A, Clark GM, Diamandis EP: Insulin-like growth factor-binding protein-3 and breast cancer survival. Int J Cancer 1998, 79:624-628.

26. Yu H, Levesque MA, Khosravi MJ, Papanastasiou-Diamandi A, Clark GM, Diamandis EP: Associations between insulin-like growth factors and their binding proteins and other prognostic indicators in breast cancer. Br J Cancer 1996, 74:1242-1247.

27. McCaig C, Perks CM, Holly JMP: Intrinsic actions of IGFBP-3 and IGFBP-5 on Hs578T breast cancer epithelial cells: inhibition or accentuation of attachment and survival is dependent upon the presence of fibronectin. J Cell Sci 2002, 115:4293-4303.

28. Mclntosh J, Perks CM, Holly JMP, Winters ZE: Insulin-like growth factor binding protein 3 (IGFBP-3) modifies epidermal growth factor (EGF)-related breast cancer growth depending upon the extracellular-matrix (ECM) [abstract]. Eur J Cancer 2004, 2:102. 
29. Ioachim E, Charchanti A, Briasoulis E, Karavasilis V, Tsanou H, Arvanitis DL, Agnantis NJ, Pavlidis N: Immunohistochemical expression of extracellular matrix components tenascin, fibronectin, collagen type IV and laminin in breast cancer: their prognostic value and role in tumour invasion and progression. Eur J Cancer 2002, 38:2362-2370.

30. McIntosh J, Clark MA, Perks CM, Holly JM, Winters ZE: Insulinlike growth factor binding protein 3 (IGFBP-3) has differential effects on epidermal growth factor (EGF) mediated proliferation in normal breast and breast cancer cells, identifying it as a potential therapeutic target [abstract]. Breast Cancer Res Treat 2003, 82(Suppl 1):S65.

31. Galea MH, Blamey RW, Elston CE, Ellis IO: The Nottingham Prognostic Index in primary breast cancer. Breast Cancer Res Treat 1992, 22:207-219.

32. Silverstein MJ, Poller DN, Waisman JR, Colburn WJ, Barth A, Gierson ED, Lewinsky B, Gamagami P, Slamon DJ: Prognostic classification of breast ductal carcinoma-in-situ. Lancet 1995, 345:1154-1157.

33. Pathology reporting in breast cancer screening 2 nd edition. Sheffield: NHS BSP Publications; 1995.

34. Elston CW, Ellis IO: Pathological prognostic factors in breast cancer: the value of histological grade in breast cancer: experience from a large study with long-term follow-up. Histopathology 1991, 19:403-410.

35. Leake R, Barnes D, Pinder S, Ellis I, Anderson L, Anderson T, Adamson R, Rhodes T, Miller K, Walker R: Immunohistochemical detection of steroid receptors in breast cancer: a working protocol. UK Receptor Group, UK NEQAS, The Scottish Breast Cancer Pathology Group, and The Receptor and Biomarker Study Group of the EORTC. J Clin Pathol 2000, 53:634-635.

36. Boland GP, Butt IS, Prasad R, Knox WF, Bundred NJ: COX-2 expression is associated with an aggressive phenotype in ductal carcinoma in situ. Br J Cancer 2004, 90:423-429.

37. Rhodes A, Jasani B, Anderson E, Dodson AR, Balaton AJ: Evaluation of HER-2/neu immunohistochemical assay sensitivity and scoring on formalin-fixed and paraffin-processed cell lines and breast tumours: a comparative study involving results from laboratories in 21 countries. $\mathrm{Am} J$ Clin Pathol 2002, 118:408-417.

38. Gill ZP: Modulation of cellular survival by insulin-like growth factor binding protein-3. PhD thesis. University of Bristol, Division of Surgery 1999

39. Skaar TC, Baumrucker CR: Regulation of insulin-like growth factor binding protein secretion by a murine mammary epithelial cell line. Exp Cell Res 1993, 209:183-188.

40. Pekonen F, Nyman T, llvesmaki V, Partanen S: Insulin-like growth factor binding proteins in human breast cancer tissue. Cancer Res 1992, 52:5204-5207.

41. Kuukasjarvi T, Tanner M, Pennanen S, Karhu R, Kallioniemi OP, Isola J: Genetic changes in intraductal breast cancer detected by comparative genomic hybridization. Am J Pathol 1997, 150:1465-1471.

42. Roylance R, Gorman P, Harris W, Liebmann R, Barnes D, Hanby A, Sheer D: Comparative genomic hybridization of breast tumors stratified by histological grade reveals new insights into the biological progression of breast cancer. Cancer Res 1999, 59:1433-1436.

43. Liu B, Lee HY, Weinzimer SA, Powell DR, Clifford JL, Kurie JM, Cohen P: Direct functional interactions between insulin-like growth factor-binding protein-3 and retinoid $X$ receptor- $\alpha$ regulate transcriptional signaling and apoptosis. $\mathrm{J} \mathrm{Biol} \mathrm{Chem}$ 2000, 275:33607-33613.

44. Perks CM, Clark M, Laurence NJ, Winters ZE, Burrows C, Holly JMP: Involvement of integrins in IGF-independent actions of IGFBP-3 in human breast epithelial cells [abstract]. In In Proceedings of 94th Annual AACR Meeting: 5-9 April 2003; Toronto Birmingham, AL: AACR; 2003:1184.

45. Perks CM, Holly JMP: Insulin-like growth factor binding protein3 (IGFBP-3) modulates the phosphorylation of focal adhesion kinase (FAK) independently of IGF in Hs578T human breast cancer cells [abstract]. Growth Horm IGF Res 1999, 9:369.

46. Gould VE, Koukoulis GK, Virtanen I: Extracellular matrix proteins and their receptors in the normal, hyperplastic and neoplastic breast. Cell Differ Dev 1990, 32:409-416.

47. Gui $Y$, Murphy $\amalg$ : Insulin-like growth factor (IGF)-binding protein-3 (IGFBP-3) binds to fibronectin (FN): demonstration of
IGF-I/IGFBP-3/fn ternary complexes in human plasma. $J$ Clin Endocrinol Metab 2001, 86:2104-2110.

48. Hollowood AD, Stewart CE, Perks CM, Pell JM, Lai T, Alderson D, Holly JM: Evidence implicating amid-region sequence of IGFBP-3 in its specific IGF-independent actions. J Cell Biochem 2002, 86:583-589.

49. Martin JL, Pattison SL: Insulin-like growth factor binding protein-3 is regulated by dihydrotestosterone and stimulates deoxyribonucleic acid synthesis and cell proliferation in LNCaP prostate carcinoma cells. Endocrinology 2000, 141:2401-2409.

50. Owens PC, Gill PG, De Young NJ, Weger MA, Knowles SE, Moyse $\mathrm{KJ}$ : Estrogen and progesterone regulate secretion of insulin-like growth factor binding proteins by human breast cancer cells. Biochem Biophys Res Commun 1993, 193:467-473.

51. Mathieu M, Vignon F, Capony F, Rochefort H: Estradiol downregulates the mannose-6-phosphate/insulin-like growth factor-II receptor gene and induces cathepsin-D in breast cancer cells: a receptor saturation mechanism to increase the secretion of lysosomal proenzymes. Mol Endocrinol 1991, 5:815-822.

52. Dowsett $M$, Harper-Wynne $C$, Boeddinghaus I, Salter J, Hills M, Dixon M, Ebbs S, Gui G, Sacks N, Smith I: HER-2 amplification impedes the antiproliferative effects of hormone therapy in estrogen receptor-positive primary breast cancer. Cancer Res 2001, 61:8452-8458

53. Balana ME, Labriola L, Salatino M, Movsichoff F, Peters G, Charreau $\mathrm{EH}$, Elizalde PV: Activation of ErbB-2 via ahierarchical interaction between ErbB-2 and type I insulin-like growth factor receptor in mammary tumor cells. Oncogene 2001 , 20:34-47.

54. Lu Y, Zi X, Zhao Y, Mascarenhas D, Pollak M: Insulin-like growth factor-I receptor signaling and resistance to trastuzumab (Herceptin). J Natl Cancer Inst 2001, 93:1852-1857. 